\title{
Ocorrência e abundância de Rynchops niger Linnaeus, no litoral de Santa Catarina, Brasil
}

\author{
Joaquim O. Branco \& Hélio A. A. Fracasso
}

Centro de Ensino em Ciências Tecnológicas da Terra e do Mar, Universidade do Vale do Itajaí. Caixa Postal 360,

\begin{abstract}
Occurrence and abundance of Rynchops niger Linnaeus in the coast of Santa Catarina, Brazil. The black skimmer inhabits the great rivers, lakes and coastal areas during the migrations, in South and North America. This work aims to make available basic information about the occurrence and abundance of the black skimmer in the coast of Santa Catarina. From April/2002 to May/2003 seasonal censuses were accomplished, and monthly in Itajaí, with aid of binoculars $10 \times 50$. The black skimmer is more frequent in the embankment of the South Bay (Florianópolis), in the summer and autumn, in the spring-summer in São José and Tijucas and in the autumn-winter in the estuary of the Saco da Fazenda (Itajaí). In this estuary, the population presented accentuated flotation along the year, with the largest abundances happening in August/2001, January/2002 and March/2003.
\end{abstract}

KEY WORDS. black skimmer, Charadriiformes, seasonal flotation.

RESUMO. O talha-mar Rynchops niger Linnaeus, 1758 habita os grandes rios, lagos e regiões costeiras durante as migrações, na América do Sul e do Norte. Esse trabalho tem por objetivo disponibilizar informações básicas sobre a ocorrência e abundância de talha-mar no litoral de Santa Catarina. Durante o período de abril/2002 a maio/ 2003 foram realizados censos sazonais (trimestrais) e mensais em Itajáí, com auxílio de binóculos 10 x 50 . O talha-mar é mais freqüente no aterro da Baía Sul (Florianópolis), no verão e outono, na primavera-verão em São José e Tijucas e no outono-inverno no estuário do Saco da Fazenda (Itajaí). Neste estuário, a população apresentou flutuações acentuadas ao longo do ano, com as maiores abundâncias ocorrendo em agosto/2001, janeiro/2002 e março/2003.

PALAVRAS CHAVE. Charadriiformes, flutuações Sazonais, talha-mar.

O talha-mar Rynchops niger Linnaeus, 1758, habita, principalmente os grandes rios e lagos do país, alcançando a região costeira durante as migrações, onde ocorre nos estuários da região norte até o Rio Grande do Sul; bem como na Argentina, Uruguai, Peru, Venezuela e Guiana, e no litoral da América do Norte (SICK 1997, Rosário 1996).

No Brasil, de acordo com KranNitz (1989), SicK (1997) a espécie nidificava na região amazônica, mas para BELTON (1984), poderia ocorrer nos bancos de areia do Rio Ibicuí (Rio Grande do Sul). Essa suposição foi confirmada por EFe et al. (2001) ao encontrarem 16 ninhos com ovos entre os meses de outubro e novembro de 1998 nessa região, sendo que a espécie ocorre em grande número nos meses de verão, na Lagoa do Peixe, no estuário da Lagoa dos Patos e em menor abundância na Praia do Cassino (Vooren \& IlHa 1995).

Em Santa Catarina, a ocorrência de $R$. niger foi notificada para a Baía Sul (Florianópolis) (Roś́rIo 1996), nas Praias de Laguna e Navegantes (SChiefler \& SoAres 1994) e nos estuários do Saco da Fazenda (Itajaí) (Branco 2000), entretanto, não existem dados disponíveis sobre sua abundância. Esse trabalho tem por objetivo disponibilizar informações básicas sobre a ocorrência e abundância de Rynchops niger no litoral de Santa Catarina.

\section{MATERIAL E MÉTODOS}

Durante o período de abril/2002 a maio/2003 foram realizados censos sazonais (trimestrais) nas populações de talha-mar do litoral de Santa Catarina. Na escolha dos locais de amostragens foram considerados a ocorrência de bandos, a localização geográfica e a possibilidade de acesso ao longo do ano, sendo selecionados seis localidades: (Araranguá) = Foz do Rio Araranguá (285' $15^{\prime \prime}$ S, 48¹9'03"W), (Florianópolis) = Aterro da Baía Sul

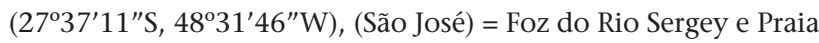

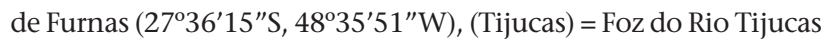
e praia $\left(27^{\circ} 14^{\prime} 08^{\prime \prime} S, 48^{\circ} 36^{\prime} 09^{\prime \prime} \mathrm{W}\right)$, (Barra Velha) = Foz do Rio Itapocú $\left(26^{\circ} 34^{\prime} 03^{\prime \prime} \mathrm{S}, 48^{\circ} 39^{\prime} 07^{\prime \prime} \mathrm{W}\right)$ e (Barra do Sul) = Canal do Linguado (26 $\left.27^{\prime} 03^{\prime \prime} \mathrm{S}, 48^{\circ} 37^{\prime} 12^{\prime \prime} \mathrm{W}\right)$. Enquanto que em Itajaí, estuário Saco da Fazenda (2654'39”S, 48³9'04”W) os censos foram mensais, durante os anos de 2001 a 2003. 

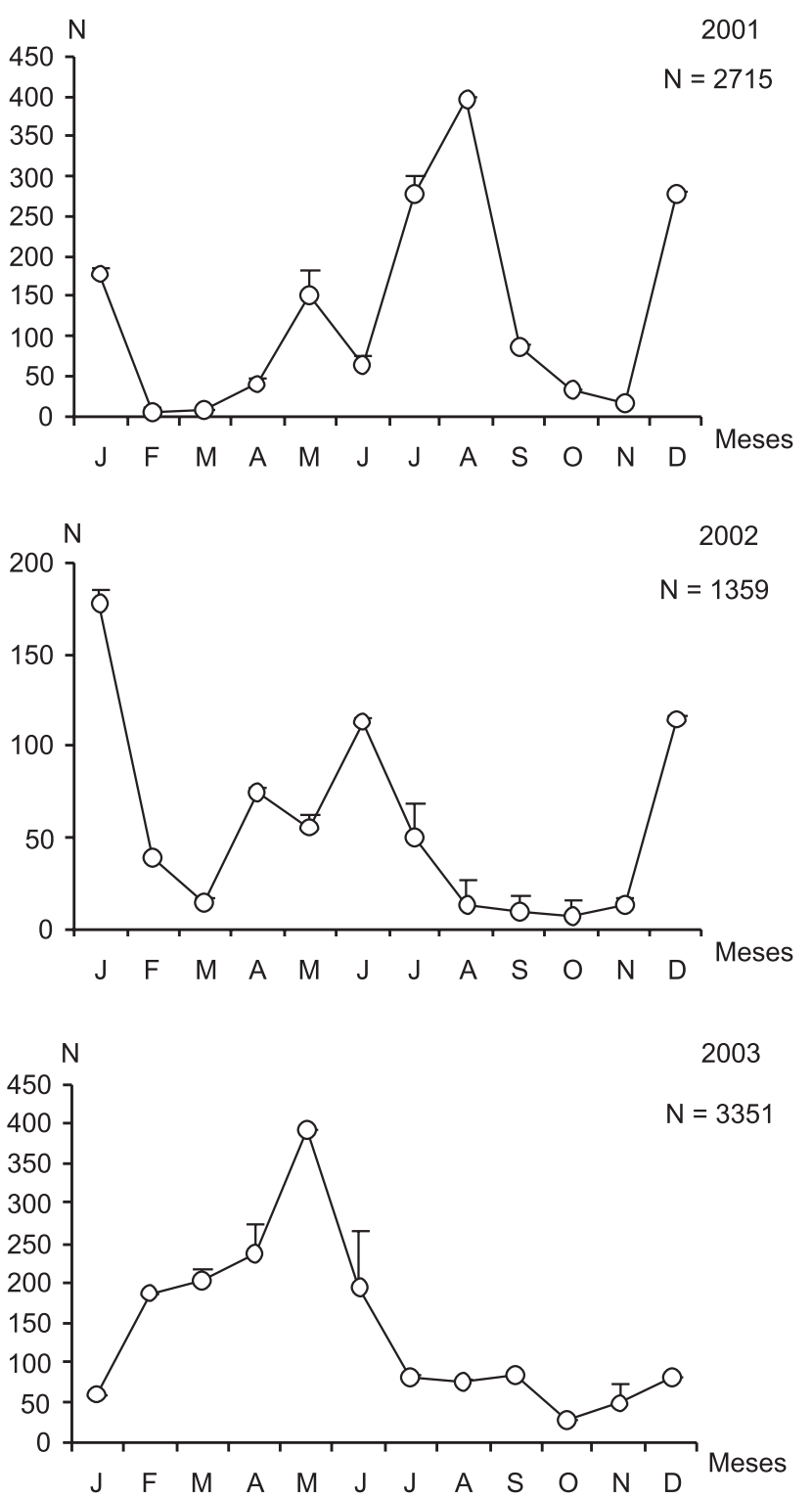

Figura 1. Abundância média mensal de Rynchops niger no estuário do Saco da Fazenda, Santa Catarina, durante o período de 2001 a 2003. Barra vertical indica o erro padrão da média.

Em cada sítio, os censos tiveram uma duração média de três horas, cobriram toda a área ocupada pela espécie, mantendo-se o mesmo horário de início. A contagem e a observação direta dos talha-mar foi realizada através de binóculos (10x50). No estuário do Saco da Fazenda, a abundância média mensal e sazonal dos talha-mar foram examinados através de um teste de ANOVA fixo (SOKAL \& Rohlf 1969), aplicado aos dados após testados à homogeneidade da variação (prova de KolmorovSmirnov).

\section{RESULTADOS E DISCUSSÃO}

O talha-mar Rynchops niger ocorre ao longo do ano no litoral de Santa Catarina, sendo mais freqüente no aterro da Baía Sul (Florianópolis), principalmente durante os meses de verão e outono, na primavera-verão em São José e Tijucas e no outonoinverno no estuário do Saco da Fazenda (Itajaí) (Tab. I).

Tabela I. Abundância média sazonal de Rynchops niger no litoral de Santa Catarina, durante o ano de 2002-2003.

\begin{tabular}{lcrrr}
\hline \multirow{2}{*}{ Locais } & \multicolumn{4}{c}{ Estações do Ano } \\
\cline { 2 - 5 } & Primavera & \multicolumn{1}{c}{ Verão } & Outono & Inverno \\
\hline Araranguá & 14,0 & 3,0 & 48,0 & 6,0 \\
Florianópolis & 103,0 & 4170,0 & 1312,0 & 162,0 \\
São José & 82,0 & 78,0 & 50,0 & 8,0 \\
Tijucas & 65,0 & 309,0 & 37,0 & 12,0 \\
Itajaí & 16,8 & 78,3 & 141,7 & 148,4 \\
Barra Velha & 0 & 0 & 8,0 & 0 \\
Barra Sul & 168,0 & 215,0 & 317,0 & 52,0 \\
\hline
\end{tabular}

Embora, não tenham ocorrido diferenças significativas $\left(\mathrm{F}_{2-33}=2,346 ; \mathrm{p}>0,05\right)$ entre a abundância média mensal de $R$. niger e os três anos de censos no estuário do Saco da Fazenda, a população apresentou flutuações acentuadas ao longo do ano, com as maiores abundâncias ocorrendo em agosto/01 (396,2 \pm $2,82)$, janeiro/2002 $(178,0 \pm 9,89)$ e março/2003 $(393,2 \pm 0,71)$. Os três anos de censos, quando reunidos em uma série sazonal (Fig. 2), evidenciam essas flutuações, indicando um incremento gradual a partir dos meses de primavera até o outono, entretanto essas diferenças não foram significativas $\left(\mathrm{F}_{2-32}=0,802\right.$; $\mathrm{p}>0,05$ ) entre as estações do ano e a abundância de talha-mar.

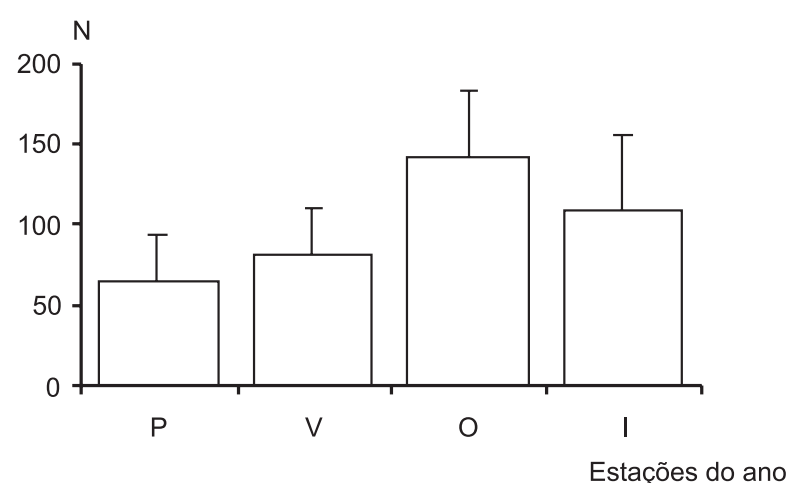

Figura 2. Abundância média sazonal de Rynchops niger no estuário do Saco da Fazenda, Santa Catarina, dados fundidos do período de 2001 a 2003. Barra vertical indica o erro padrão da média.

Para Vooren \& Chiaradia (1990) os exemplares observados durante os meses de verão na Praia do Cassino (Rio Grande do Sul) pertencem à populações que reproduzem no final do

Revista Brasileira de Zoologia 22 (2): 430-432, junho 2005 
inverno em áreas próximas ou no Rio Grande do Sul. Apesar da ausência de informações sobre a origem das populações que ocorrem ao longo do ano no litoral catarinense, é possível que esses exemplares tenham uma origem comum.

Durante o dia, os bandos de talha-mar foram observados pousados nas coroas arenosas das praias, foz de rios e estuários, cuidando da plumagem e descansando. Comportamento semelhante foi observado nas populações do litoral catarinense (Rosário 1996) e gaúcho (Vooren \& Chiaradia 1990).

Nessa espécie ocorre dimorfismo sexual entre os adultos, sendo considerados machos os exemplares acima de $290 \mathrm{~g}$ e fêmeas abaixo de $270 \mathrm{~g}$ (ERwIN 1977). Enquanto para QUINN (1990), os machos pesam entre 260 a $392 \mathrm{~g}$ e as fêmeas entre 212 a 292 g. No presente estudo, apesar do maior tamanho de alguns talha-mar, não foi possível identificar com segurança os sexos, entretanto, essa divisão seria eficiente nas colônias de reprodução. Outro fato interessante nessa espécie é a nidificação na América do Norte, na região litorânea em bancos de areia e praias arenosas (BURGER 1982, ERwIN 1977), enquanto que na América do Sul, ocupa as margens expostas dos grandes rios (Sick 1997, Escalante 1970, Klimaitis \& Moschione 1984).

\section{REFERÊNCIAS BIBLIOGRÁFICAS}

Belton, W. 1984. Birds of Rio Grande do Sul, Brazil. Part. 1. Rheidae through Furnariidae. Bulletin of American Museum of Natural History, New York, 178: 371-631.

Burger, J. 1982. The role of reproductive success in colony-site selection and abandonment in black skimmers (Rynchops niger). Auk, Fayetteville, 99: 109-115.

BRAnCo, J.O. 2000. Avifauna associada ao estuário do Saco da Fazenda. Revista Brasileira de Zoologia, Curitiba, 17 (2): 387-394.

Efe, M.A; L. Bugoni; L.V. Mohr; A. Scherer; S.B. Scherer \& O.P.
BAIRRO. 2001. First-known Record of breeding for the black skimmer (Rynchops niger) in a mixed colony in Iticuí river, Rio Grande do Sul state, southern Brazil. International Journal Ornithology, Belo Horizonte, 4 (2): 103-107.

ERwIN, R.M. 1977. Black skimmer breeding ecology and behavior. Auk, Fayetteville, 94: 709-717.

Escalante, R. 1970. Aves marinas del Rio de la Plata y aguas vecinas del Oceano Atlántico. Montevideo, Editora Barrero y Ramos, 199p.

Klimaitis, J.F. \& F. Moschione. 1984. Observaciones sobre nidificacion asociada en Charadrius collaris, Sterna superciliaris y Rynchops niger en el Rio Uruguay, entre rios, Argentina. El Hornero, Buenos Aires, 3: 197-202.

KRANNITZ, P.G. 1989. Nesting biology of black skimmers, largebilled terns, and yellow-billed terns in Amazonian Brazil. Journal of field ornithology, Columbus, 60 (2): 216-223.

QuinN, J.S. 1990. Sexual size dimorphism and parental care patterns in a monomorphic and a dimorphic larid. Auk, Fayetteville, 107: 260-274.

RosÁrio, L.A. 1996. As aves em Santa Catarina: Distribuição geográfica e meio ambiente. Florianópolis, FATMA, 329p.

SICK, H. 1997. Ornitologia Brasileira. Rio de Janeiro, Editora Nova Fronteira, 912p.

SOKAL, R.R. \& F.J. RoHlf. 1969. Biometry, the principles and practices of statistics in biological research. San Francisco, W.H. Freeman, 776p.

SChiefler, A.F. \& M. SoARES. 1994. Estudo comparativo da avifauna das praias de Navegantes e Laguna, Santa Catarina. Biotemas, Florianópolis, 7 (1/2): 31-45.

Vooren, C. \& A. Chiaradia. 1990. Seasonal abundance and behaviour of costal birds on Cassino Beach, Brazil. Ornitologia Neotropical, Québec, 1: 9-24.

Vooren, C. \& H.H. IlHa. 1995. Guia das aves comuns da costa do Rio Grande do Sul. Imago Maris, Rio Grande, 2 (1): 1-23.

Recebido em 17.VIII.2004; aceito em 24.V.2005. 